\title{
Cardiac aneurysm after myocardial infarction
}

\author{
BERNARD M. GRODEN \\ M.B., Ch.B., M.R.C.P.(Glasg.), M.R.C.P.(Edin.) \\ WILSON B. JAMES \\ M.B.; Ch.B., F.F.R. \\ IAN MCDICKEN \\ M.B., Ch.B. \\ The Departments of Medicine, Radiology and Pathology, Southern General Hospital, Glasgow, S.W.1
}

\begin{abstract}
Summary
Ten cases of post-infarction cardiac aneurysm have been described in detail. Many of the patients had survived for several years after the infarction which was held to be responsible for the formation of the aneurysm. It is suggested that in most cases the diagnosis can be made on the basis of a PA chest radiograph combined with careful cardiac fluoroscopy. If surgery is contemplated because of cardiac failure which does not respond to medical treatment or because of embolic phenomena not controlled by anticoagulant therapy, left heart angiography and coronary arteriography are indicated.
\end{abstract}

\section{Introduction}

The term aneurysm was used by early writers to describe generalized cardiac enlargement. The earliest report of an aneurysm of the ventricle was made by John Hunter (1757). The incidence of aneurysm in autopsy reports of patients after a myocardial infarction has varied from 3\% (Dubnow, Burchell \& Titus, 1965) to $38 \%$ (Parkinson, Bedford \& Thomson, 1938). The diagnosis is rarely made in life although Master et al. (1940) found abnormalities of pulsation of the cardiac contour after myocardial infarction in $73 \%$ and Kurtzman \& Lofstrom (1963) in $78 \%$ of patients. Not all of these patients had aneurysms but recently Gorlin, Klein \& Sullivan (1967) demonstrated twenty-four cases of aneurysm by left heart angiography, in a series of 100 patients with coronary artery disease, and two of the present authors (Groden \& James, 1968) have found radiological features suggestive of aneurysm in $20 \%$ of patients who had survived a myocardial infarction more than 3 months previously.

We describe here ten cases of ventricular aneurysm following myocardial infarction seen in recent years at this hospital.

\section{Case reports}

Case 1: P.McC., died age 69

For 1 week before admission to hospital in December 1965, this patient had been suffering from anginal chest pain on exertion, and about $24 \mathrm{hr}$ prior to admission he began to experience protracted chest pain which was accompanied by sweating and breathlessness.

On admission his pulse was $48 / \mathrm{min}$, regular. BP $130 / 80 \mathrm{mmHg}$. Heart sounds were of poor quality and there were crepitations at both bases. ECG showed the changes of a recent transmural antero-septal infarction and sinus bradycardia. The serum glutamic oxalacetic transaminase (SGOT) level rose to 120 units (Dade).

At the time of discharge 5 weeks later his ECG continued to show R-ST elevation in the precordial leads. He returned to normal activity and was followed up as an outpatient. Three months later, cardiac screening showed a marked prominence of the left heart border in the right anterior oblique projection (Fig. 1) which was thought to be an aneurysm. ECG still showed $Q$ waves and $R$-ST elevation. One year after the original incident he sustained a further infarction and was re-admitted to hospital. His ECG at this time revealed posterior ischaemia in addition to the above changes. A temporary phase of A.V. dissociation occurred with frequent ventricular extra-systoles and small $R$ waves appeared in $V_{2}$, $V_{3}$ and $V_{4}$.

He died suddenly on 26 December 1966.

Necropsy: The heart was enlarged $(530 \mathrm{~g})$ with both left and right ventricular hypertrophy, the walls being 24 and $9 \mathrm{~mm}$ in thickness, respectively. Above the apex of the heart, there was a large aneurysmal dilatation overlying which was a fibrinous pericarditis with adhesions obliterating the pericardial space (Fig. 2). Section through the left ventricle showed the aneurysm filled with well 


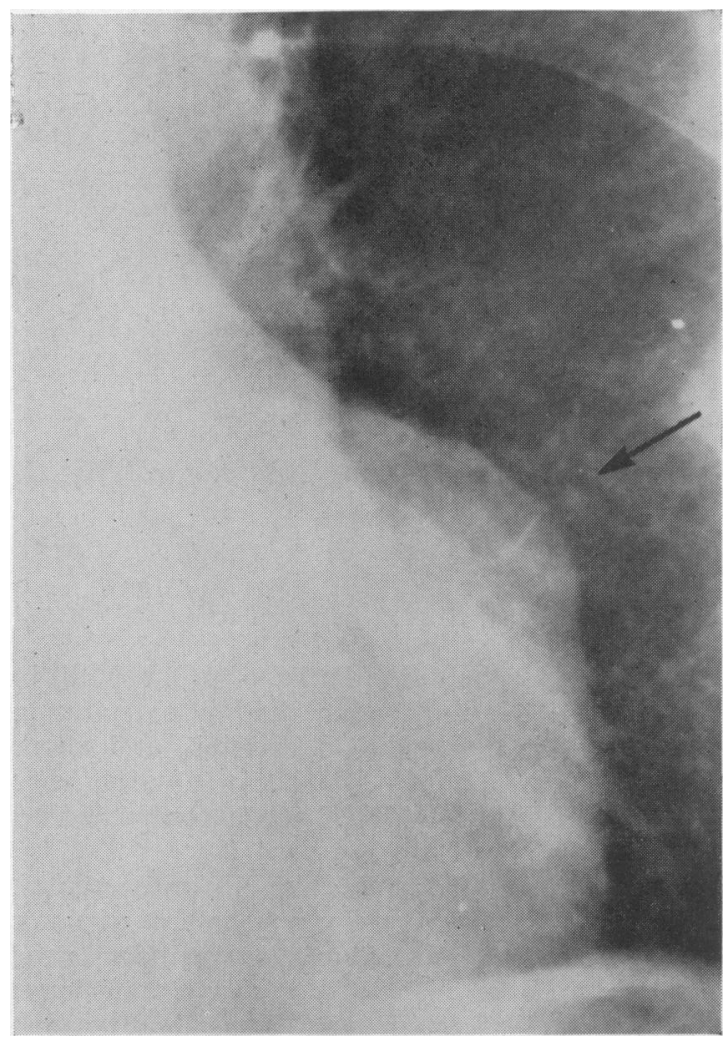

Fig. 1. Case 1. P.McC. Prominence of left heart border in RAO projection.

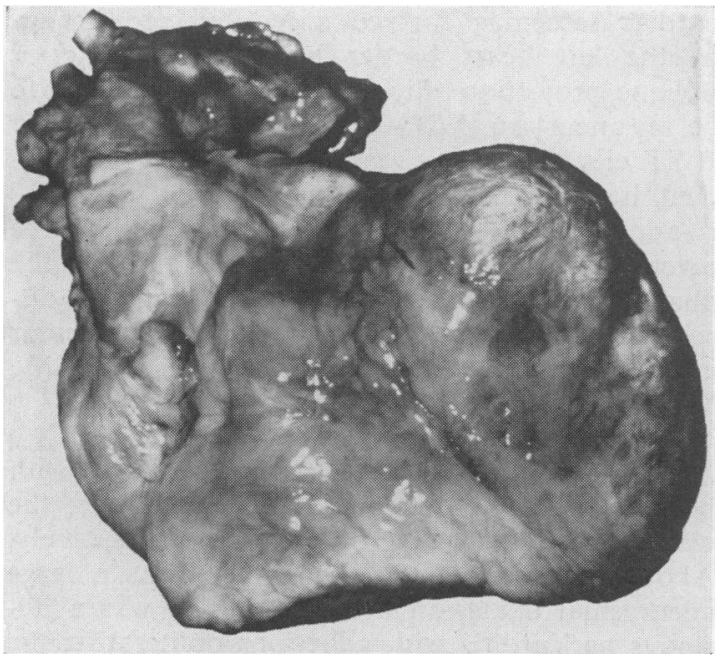

FIG. 2. Case 1. P.McC. Showing aneurysm above the apex of the heart. organized, firmly adherent thrombus (Fig. 3). The wall of the aneurysm consisted of fibrous tissue. The I.V. septum showed old and recent infarctions and histological examination of sections from the I.V. septum confirmed this. Sections from the wall of the aneurysm showed it to consist of dense acellular scar tissue with underlying organized thrombus. There was no muscle in this tissue.

Comment. The aneurysm was almost certainly the result of the infarction in November 1965. Death was due to arrhythmia following the second infarction.

\section{Case 2: A.E., died age 70}

This patient was admitted to hospital in November 1965 for investigation of cardiac failure. Pulse rate $96 / \mathrm{min}$, BP $165 / 85 \mathrm{mmHg}$. The apex beat was forceful, a third heart sound was present at the apex, and crepitations were heard at the bases. ECG showed marked left axis deviation and $Q$ waves in leads $V_{1}$ to $V_{3}$. R-ST segments were elevated in leads $V_{1}$ to $V_{4}$. Chest $X$-ray showed cardiac enlargement with an area of calcification at the apex (Fig. 4). She improved with bed rest, digoxin and diuretics and was discharged home

The patient was re-admitted 1 year later with a totally irregular pulse rate of $130 / \mathrm{min}$. The apex was $15 \mathrm{~cm}$ from the mid-line in the sixth left inter-
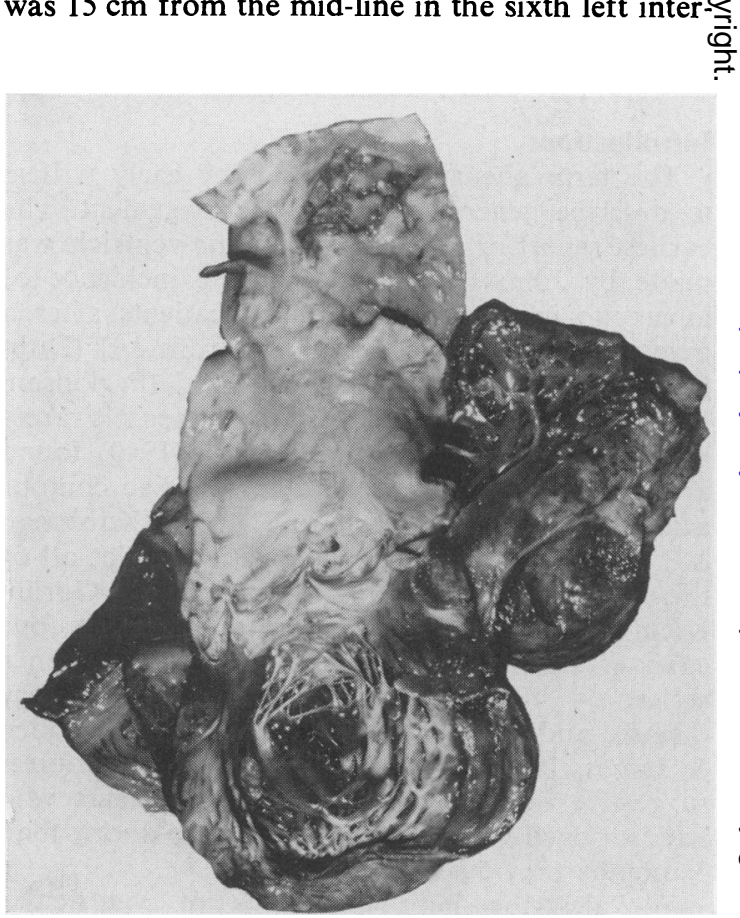

Fig. 3. Case 1. P.McC. Section of heart through aneurysm, which is filled with adherent thrombus. 


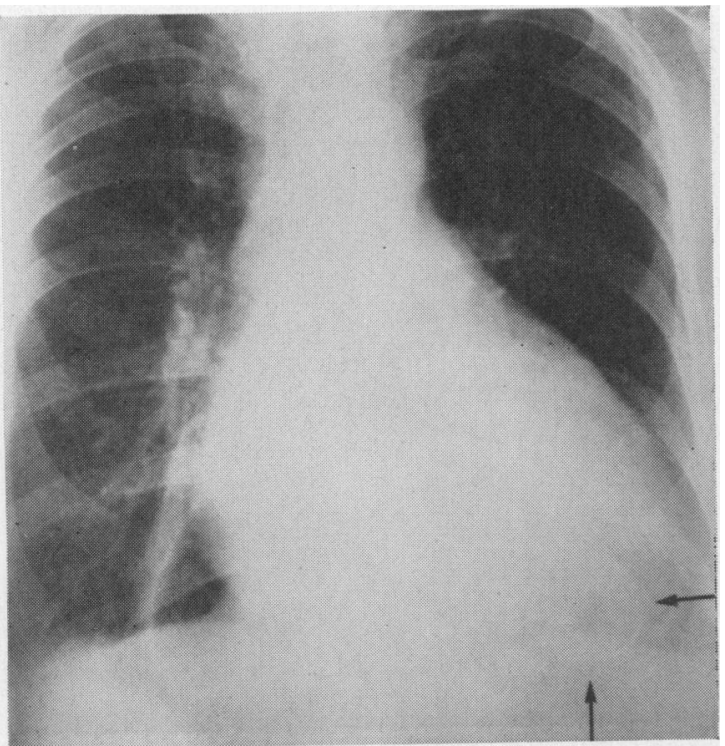

Fig. 4. Case 2. A.E. Chest radiograph (PA) showing calcified aneurysm at the apex of the heart.

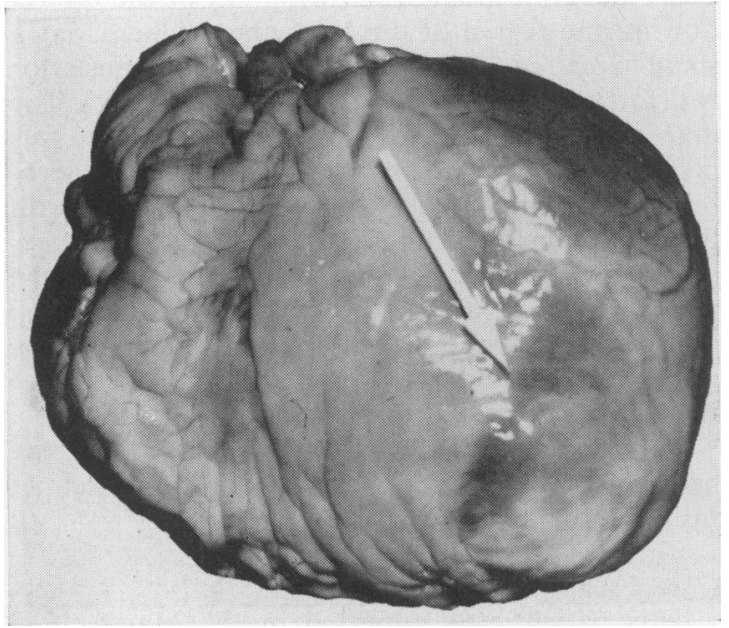

Fig. 5. Case 2. A.E. Showing aneurysm at apex of heart.

space. The heart sounds were muffled and there was a systolic murmur at the apex. Crepitations were heard at both bases. ECG, apart from atrial fibrillation, was very similar to the one recorded previously. Chest X-ray showed cardiac enlargement and pulmonary congestion and the area of calcification was again noted. On this occasion a diagnosis of cardiac aneurysm was made. She did not respond to treatment and died on 17 January 1967 of bronchopneumonia and congestive cardiac failure.

Necropsy. The heart was considerably enlarged $(540 \mathrm{~g})$. Near the apex, in the anterior wall of the left ventricle, there was a large calcified aneurysm (Fig. 5). On opening the heart the left ventricle was found to be markedly hypertrophied $(30 \mathrm{~mm}$ in thickness). The aneurysmal opening was $3 \mathrm{~cm}$ in diameter and the wall of the aneurysm was thin, fibrotic and calcified. There was no thrombus in the sac. There were no valve defects present. The coronary arteries were narrowed by atheroma but no occlusion by thrombus could be demonstrated. Histological examination of sections from the left ventricle showed extensive ischaemic changes in all areas examined. No recent infarction was seen. Sections of the wall of the aneurysm showed fibrosis, hyalinization of the connective tissue and calcium deposition in the pericardium. In the subendocardial region there was a relatively thick continuous band of viable cardiac muscle.

Comment. In retrospect the ECG abnormalities detected in November 1965 were not the result of recent infarction but resulted from an infarction at some undetermined time in the past.

\section{Case 3: E.L., died age 53}

This patient who had a previous history of hypothyroidism suddenly developed severe retrosternal chest pain on 5 December 1966 and was thought to have sustained a myocardial infarction. This was confirmed by an ECG which showed the changes of an early transmural antero-septal infarction and a rise of SGOT. Left heart failure developed and she died on 22 January 1967. ECG throughout had shown R-ST elevation and Q waves and there was little evidence of sequential change although she had been observed for about 6 weeks in hospital.

Necropsy. The heart was slightly enlarged $(400 \mathrm{~g})$, with a large bulge on the anterior wall of the left ventricle. The orifice of this aneurysm was $8 \mathrm{~cm}$ in diameter (Fig. 6). At the site of the aneurysm the wall was extremely thin and fibrotic. The valves were normal. The coronary arteries were extensively atheromatous and the descending branch of the left coronary artery was occluded. Pericardial adhesions were present over the aneurysm and obliterated the pericardial space. (No sections were examined histologically.)

Comment. The appearance of the heart at autopsy suggested that the aneurysm was exerting an haemodynamic effect, and may have been partly responsible for heart failure. 


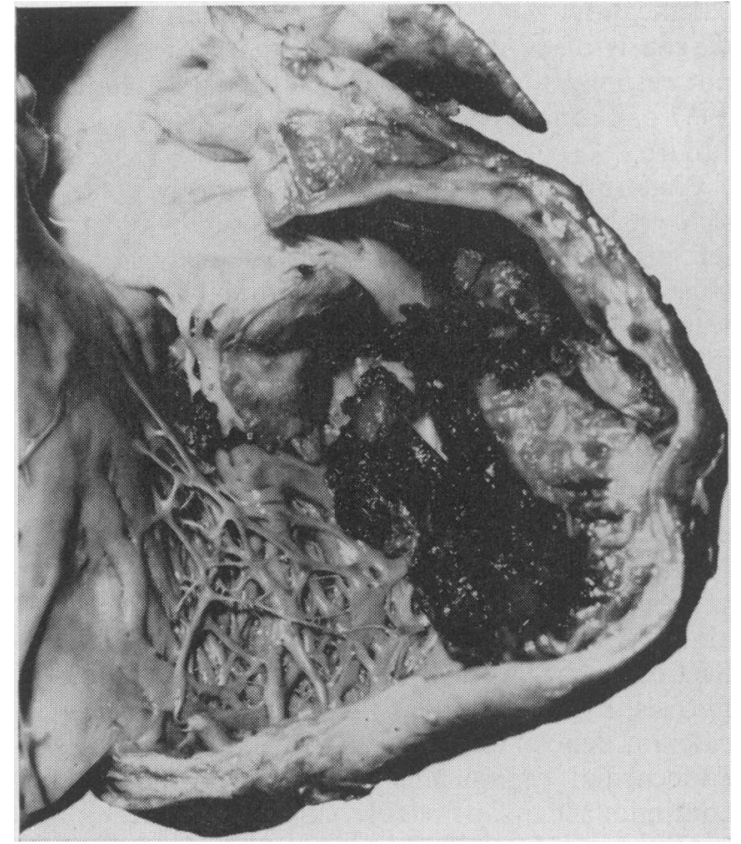

FIG. 6. Case 3. E.L. Section of heart showing large thin walled aneurysm of left ventricle with thrombus.

\section{Case 4: A.C., died age 63}

This patient was admitted to hospital on 4 April 1967 with severe central chest pain radiating to his arm, of $2 \mathrm{hr}$ duration. Pulse rate $92 / \mathrm{min}$ regular, BP $170 / 90 \mathrm{mmHg}$. Acute myocardial infarction was diagnosed and confirmed by electrocardiographic changes of anterior transmural infarction, and a rise of SGOT and ESR. He was treated with bed rest and anticoagulants. His blood pressure fell after admission but gradually improved. Fourteen days after the infarction his cardiac output as estimated by the photo-electric earpiece dye dilution technique, using Coomassie blue, was $6.81 / \mathrm{min}$. The ECG continued to show $Q$ waves and R-ST elevation and aVR was upright. A ward radiograph revealed pulmonary congestion, bilateral pleural transudates, slight cardiac enlargment and a small 'step' on the left heart border which was thought to represent an aneurysm (Fig. 7). Cardiac failure became worse, his blood pressure fell and despite treatment with diuretics, digoxin and oxygen, the patient died on 17 May 1967. Cardiac output $48 \mathrm{hr}$ prior to his death had fallen to $2.6 \mathrm{l} / \mathrm{min}$.

Necropsy: The heart was enlarged $(450 \mathrm{~g})$ due mainly to left ventricular hypertrophy (left ventricular wall thickness was $24 \mathrm{~mm}$ ). On the antero-lateral aspect of the left ventricle there was a large aneurysm almost completely filled with

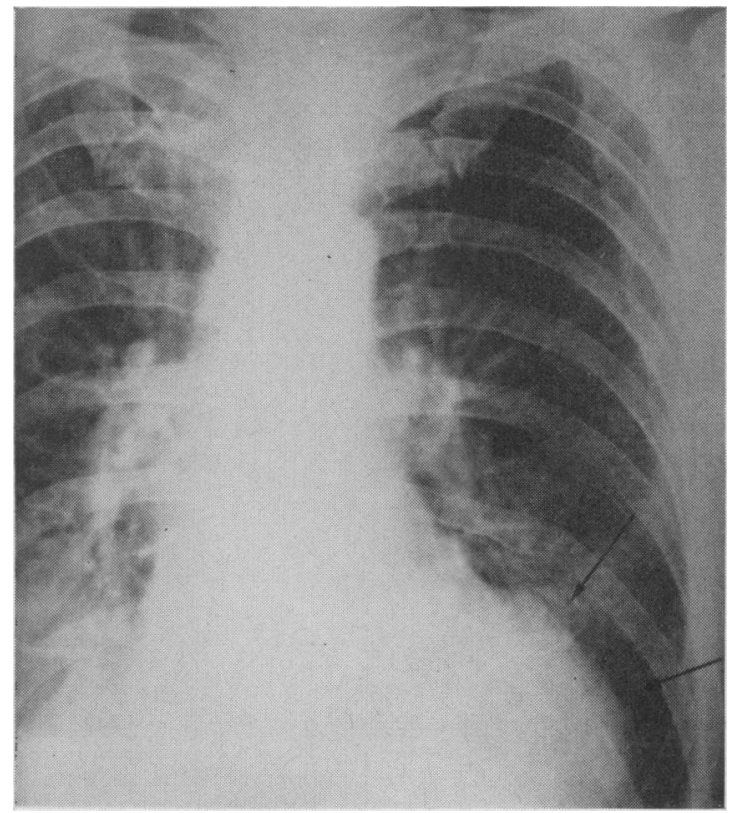

Fig. 7. Case 4. A.C. Chest radiograph showing 'step' on left heart border.

layered thrombus (Fig. 8). The area of the aneurysm almost coincided with that of the infarction. In the region of the I.V. septum, there was a small area of recent infarction. The posterior wall of the left ventricle was hypertrophied. The descending branch of the left coronary artery was occluded by thrombus overlying an area of atherosclerosis. There was extensive pericarditis with firm adhesions over the aneurysm. Histological examination showed extensive infarction of the anterior wall of the left ventricle with stretching and thinning of the tissue forming the wall of the aneurysm. Bundles of viable muscle fibres were found in the wall of the aneurysm.

Comment. In this case too the aneurysm may have been partly responsible for the onset of failure and death.

\section{Case 5: J.W., died age 51}

This patient was admitted on 31 March 1967 with chest pain which had been present for several hours. Pulse rate $84 / \mathrm{min}$, BP $120 / 80 \mathrm{mmHg}$. A diagnosis of acute myocardial infarction was confirmed by a rise of SGOT and of ESR and the typical electrocardiographic changes of an extensive transmural anterior myocardial infarction. Three days after admission she developed further chest pain and pericardial friction was heard. ECGs continued to show the changes of acute 
myocardial infarction and persistent R-ST elevation. A chest $X$-ray revealed cardiac enlargement with some atelectasis at both lung bases. She died on 18 April 1967.

Necropsy. The heart size was normal $(380 \mathrm{~g})$. The pericardial sac was filled with ante-mortem blood clot and there were fibrinous adhesions present between the heart and the pericardium. An aneurysm $(6 \mathrm{~cm}$ in diameter) extended from the apex of the left ventricle to the I.V. septum. The wall of the aneurysm was composed of fibrous tissue which had ruptured at several places and at one point there was communication between the ventricles (Fig. 9). Within the aneurysm there was organized ante-mortem clot and several thrombi were present in the right ventricle. An area of more recent infarction was present in the I.V. septum. The coronary arteries showed marked atherosclerotic changes and the descending branch of the left coronary artery was occluded by recent thrombus.

Sections from the aneurysm showed the wall to consist of organizing infarction with some areas of viable muscle.

Comment. This is an example of rupture of an aneurysm. It is unusual for this to occur in an aneurysm of long standing. The histological appearances in this case were compatible with the clinical impression that the aneurysm dated from the infarction at the time of admission.

\section{Case 6: W.R., died age 79}

This patient was admitted on 19 May 1967 with

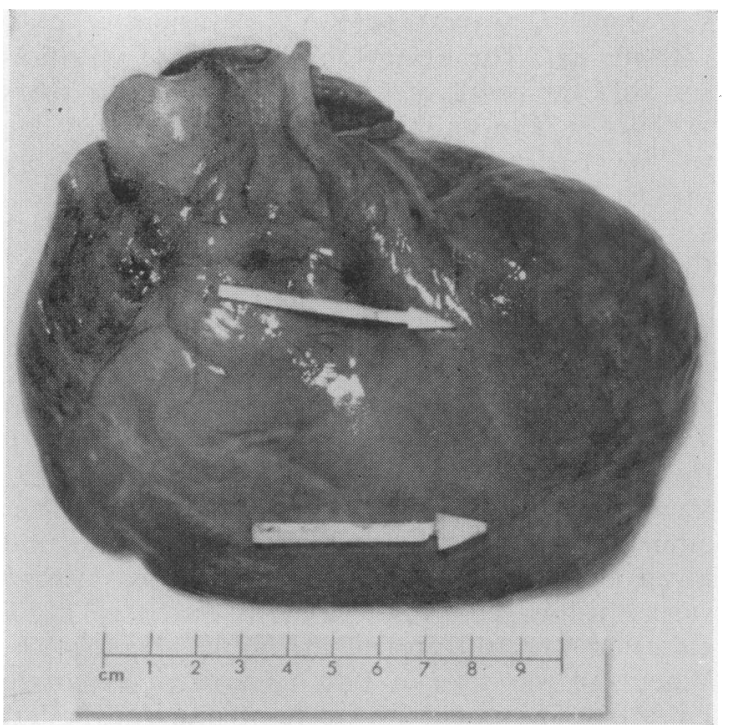

Fig. 8. Case 4. A.C. Showing aneurysm coinciding with area of infarction. chest pain of $48 \mathrm{hr}$ duration radiating to the left arm and through to the back. Pulse rate $85 / \mathrm{min}$ regular, with good volume. BP $190 / 110 \mathrm{mmHg}$. The apex beat was heaving and was localized in the fifth intercostal space outwith the mid-clavicular line. A pericardial friction rub was heard all over the praecordium. Heart sounds were otherwise normal. ECG showed the changes of acute transmural antero-septal myocardial infarction and non-penetrating inferior infarction. The patient died suddenly 18 days after admission. At the time of death the R-ST segment was still elevated.

Necropsy. The heart was considerably enlarged, weighing $730 \mathrm{~g}$, mainly due to left ventricular hypertrophy. The wall of the left ventricle was thickened $(26 \mathrm{~mm})$, at the apex of the left ventricle there was a large thin-walled aneurysm. The myocardium showed extensive infarction of the anterior and lateral surface of the left ventricle with more recent infarction of the I.V. septum. On its endocardial surface, the aneurysm was covered with friable thrombus while on the pericardial surface there was extensive haemorrhagic pericarditis, with numerous fine adhesions (Fig. 10). The wall of the aneurysm was found to consist of organizing infarct. In the subendocardial region viable cardiac muscle persisted. The myocardium of the posterior wall of the ventricle was hypertrophied.

Comment. This is another example of aneurysm occurring soon after infarction.

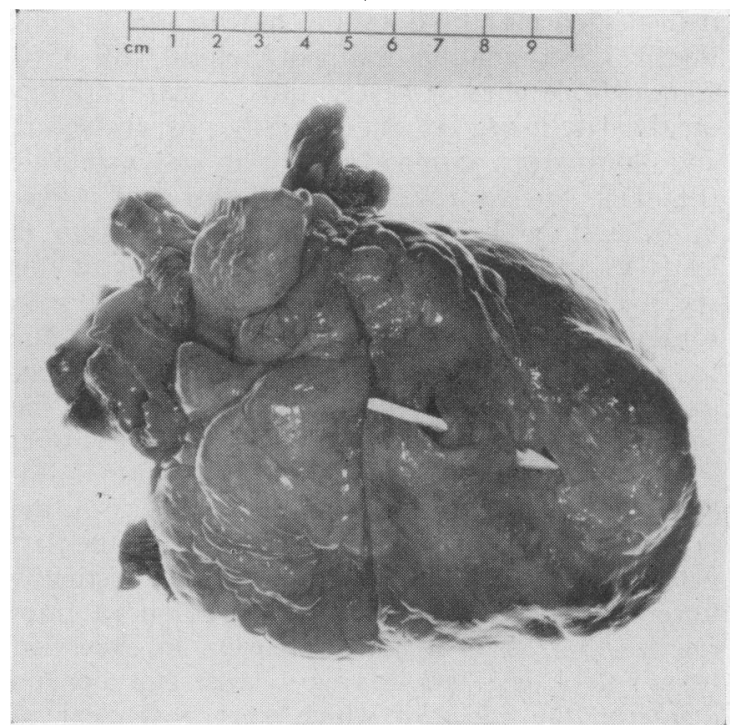

FIG. 9. Case 5. J.W. Showing the heart with rupture of aneurysm. 


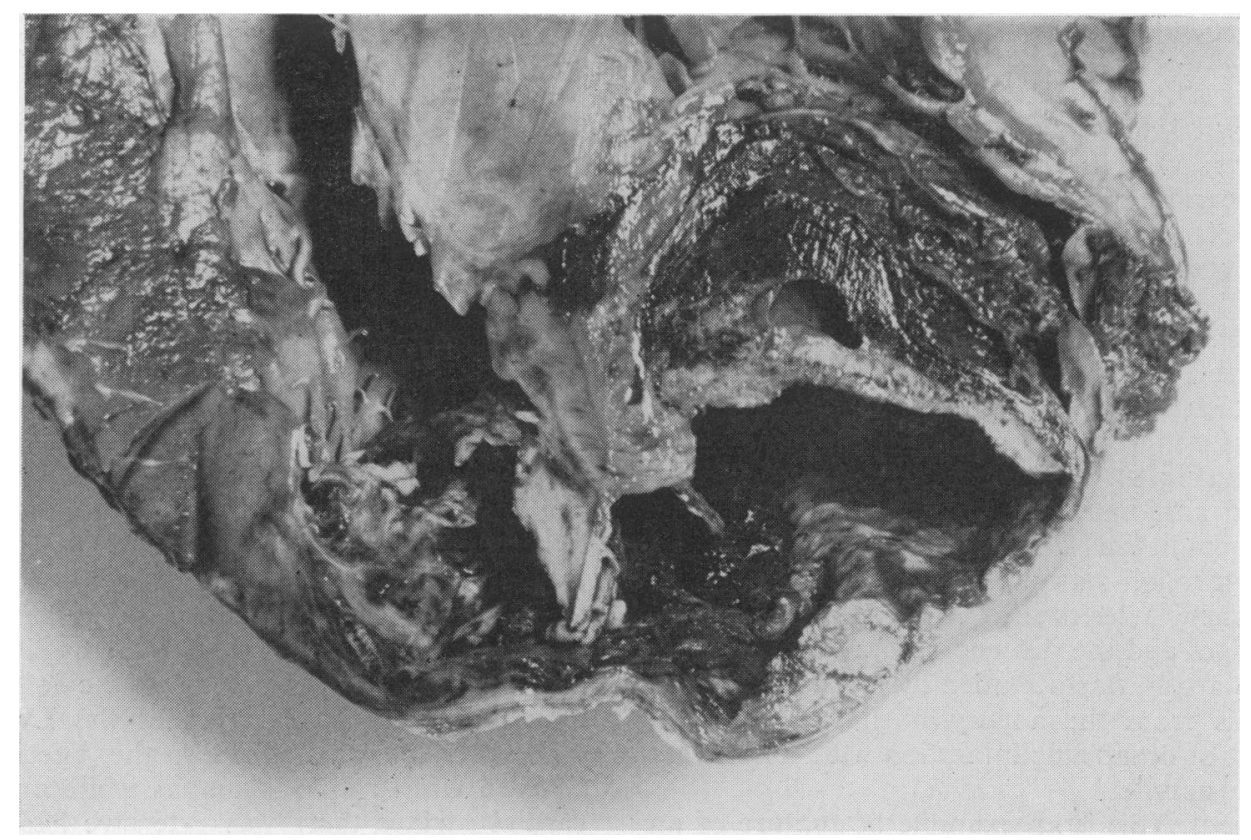

Fig. 10. Case 6. W.R. This shows the heart cut through the aneurysm. There is gross left ventricular hypertrophy.

Case 7: A.H. (born 30 June 1909)

This patient was referred to hospital in April 1965 because of breathlessness on exertion of almost 2 years duration. He also complained of attacks of palpitation and stabbing praecordial pain of 5-6 months duration, but no true angina. Physical examination was not helpful. BP 130/ $75 \mathrm{mmHg}$. A chest $\mathrm{X}$-ray revealed a marked bulge on the left heart border suggestive of aneurysm, and fluoroscopy confirmed that it was expansile (Fig. 11). An electrocardiogram showed $Q$ waves in leads $1, a V L, V_{1}-V_{5}$ and $R-S T$ elevation in leads $V_{2}$ and $V_{3}$. Further close questioning at this stage elicited history of an attack of chest pain some years previously which could have been due to myocardial infarction. A diagnosis of postinfarction cardiac aneurysm was made and the patient underwent aneurysmectomy on 20 October 1965 under heart-lung bypass, at $30^{\circ} \mathrm{C}$ (Mr T. M. Welsh). The aneurysm was found to occupy the proximal half of the anterior panel of the left ventricle, the remainder of which was distinctly fibrotic. It was filled with darkly coloured fragmented clot. A firm fibrous margin in excess of $0.5 \mathrm{~cm}$ thick was left leaving a large gap $5 \mathrm{~cm}$ in diameter, the edges of which were well clear of vessels. A circle of pericardium was sutured to the inner aspect of the margin and the gap closed with a piece of dacron. The post-operative course was complicated by a short-lasting confusional state and occasional chest pain but subsequently he made a good recovery although he is still breathless on exertion and his electrocardiogram still shows $Q$ waves and R-ST elevation.

Comment. The aneurysm in this case was presumably the result of the infarction several years previously. The stabbing pain may have been due to the pericarditis which is almost invariably present in association with aneurysm.

\section{Case 8: I.S. (born 19 September 1898)}

This patient was admitted to hospital in 1961 with chest pain. A clinical diagnosis of myocardial infarction was confirmed by electrocardiographic changes of an inferior transmural infarction $(Q$ waves, in 2, 3 and aVF and R-ST elevation in these leads) and rise of SGOT and ESR. BP 145/ $90 \mathrm{mmHg}$. She continued to have chest pain after admission and was treated in bed for 6 weeks and given anticoagulants. She was discharged after 9 weeks in hospital. At the time of discharge R-ST elevation was still present in leads 2, 3 and aVF. When she was seen in 1965 an area of expansile pulsation was noted in the third and fourth left intercostal spaces and an ECG still showed R-ST elevation in the inferior leads. A PA chest radio- 


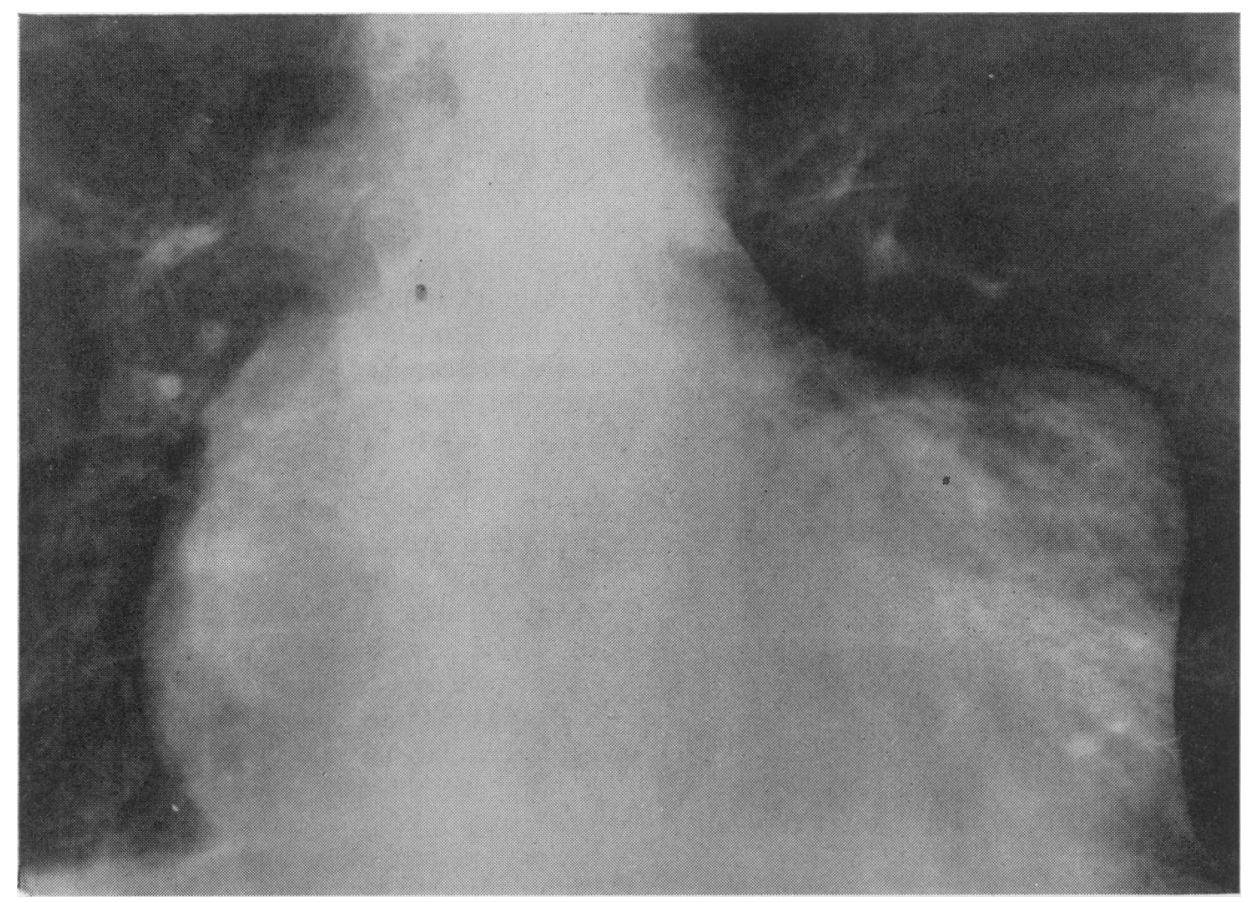

FIg. 11. Case 7. A.H. PA chest radiograph showing large aneurysm, left heart border.

graph revealed a bulge on the left heart border and cardiac screening showed paradoxical pulsation (Fig. 12). Subsequently she has developed congestive failure which has been controlled with digoxin and diuretics. A recent electro-cardiogram showed R-ST elevation in 2, 3 and aVF, potential heart block and delayed intraventricular conduction.

Comment. This is the only patient in the present series in whom clinical examination would suggest the diagnosis of cardiac aneurysm.

\section{Case 9: D.McD. (born 15 November 1907)}

This patient was admitted to hospital on 13 July 1966. It was believed that he suffered from rheumatic heart disease, since he had been known to be in atrial fibrillation for about 12 years. He was in mild congestive failure. Pulse $100 / \mathrm{min}$ totally irregular, BP 140/85 mmHg. Apex beat $11 \mathrm{~cm}$ from the mid-line and heaving in character. There were systolic and diastolic murmurs at the apex. The ECG confirmed atrial fibrillation with occasional ventricular extrasystoles. $Q$ waves and $R-S T$ elevation were present in $V_{1}$ and $V_{2}$, and $T$ waves were inverted in $V_{5}$ and $V_{6}$. There was right axis deviation and aVR was biphasic. It was considered that these ECG changes were suggestive of old anterior myocardial infarction with aneurysm formation. Cardiac screening showed cardiac enlargement, with prominence of the left ventricle. There was an aneurysmal bulge of the anterior surface of the heart best seen in the right anterior oblique projection, similar to that shown in Fig. 1 (Case 1). Treatment with digoxin and diuretics produced substantial improvement and he was allowed home.

Comment. The clinical and radiological features of this case are more suggestive of post-infarction cardiac aneurysm than of mitral valve disease, although both conditions could be present. The murmurs can be explained by the passage of blood to and fro through the neck of the aneurysm.

\section{Case 10: W.T. (born 12 March 1904)}

This patient was referred to the Chest Clinic of the hospital in May 1967 because of breathlessness on exertion. He gave a history of a myocardial infarction 15 years previously and physical examination revealed a mild degree of congestive cardiac failure. Pulse rate $90 / \mathrm{min}$ with extrasystoles, BP $130 / 80 \mathrm{mmHg}$. ECG showed LBBB and sinus rhythm. Chest $\mathrm{X}$-ray revealed a large plaque of calcium along the left heart border which was thought to be calcification in the wall of a cardiac 


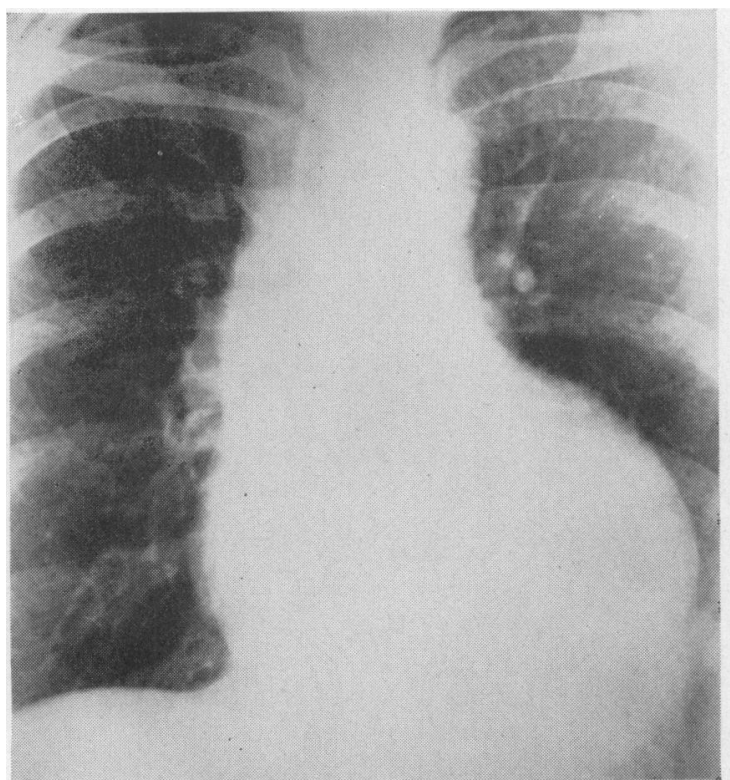

FIG. 12. Case 8. I.S. Showing bulge on left heart border.

aneurysm (Fig. 13). Cardiac fluoroscopy confirmed the presence of a bulge which exhibited diminished pulsation.

Comment. The aneurysm is almost certainly the result of an infarction 15 years before.

Details of these ten patients are shown in Table 1.

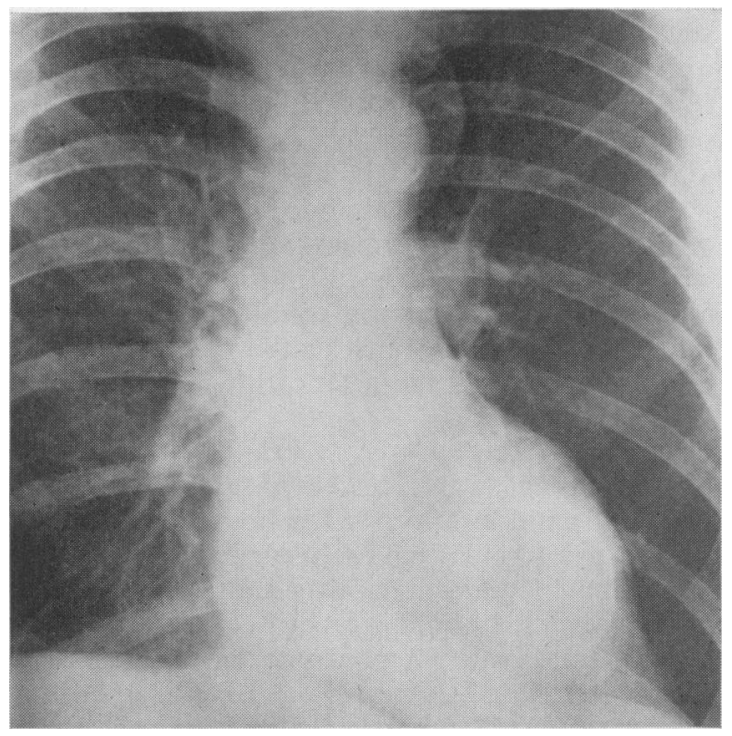

FIG. 13. Case 10. W.T. Showing plaque of calcium along left heart border.

\section{Discussion}

Schlichter, Hellerstein \& Katz (1954) and Dubnow et al. (1965) state that the presence of an aneurysm has serious prognostic significance. This has not been borne out by the studies of Douglas, Sferrazza \& Marici (1962) and of Abrams et al. (1963). In the present series six of the patients described survived for more than 1 year after infarction with aneurysm formation, and three of these for more than 5 years. Four patients are still alive. In seven patients the diagnosis was made in life. Physical signs suggestive of aneurysm were present in only one patient (case 8) and diagnosis in the others was made on the basis of radiological and/or electrocardiographic findings. Four aneurysms were discovered in the early stages after the infarction, and in another patient the diagnosis was suggested by absence of sequential change on the electrocardiogram after 3 months, and confirmed by cardiac fluoroscopy. The other cases were diagnosed at varying intervals up to 15 years after the original incident. One aneurysm ruptured in the early stages (Case 5) and three patients died in congestive cardiac failure to which the aneurysm probably contributed in two. In one patient, further infarction was the cause of death and in this patient it seems unlikely that the aneurysm was exerting a functional effect since it was filled with thick thrombus. One patient has undergone surgery for the repair of his aneurysm and three patients are receiving medical treatment only.

Inadequate bed rest in the early stages after the infarction is said to predispose to aneurysm formation (Moyer \& Hiller, 1951; Schlichter et al., 1954). Three of the cases reported were not rested at the time of the myocardial infarction but all of the other patients had adequate periods of bed rest. A recent clinical study has suggested that schemes of earlier mobilization after infarction do not result in an increased incidence of aneurysm formation (Groden, Allison \& Shaw, 1967).

Hypertension has been implicated in aneurysm formation because of the high pressures to which the healing infarct is exposed. It has not been a factor in any of our patients nor did Dubnow et al. (1965) feel that it was an important factor.

An expansile aneurysm can absorb a considerable amount of cardiac output and behave functionally in the same way as mitral incompetence while a rigid, fibrosed or calcified aneurysm is unlikely to exert a significant functional effect. In Case 4 the cardiac output fell from 6.8 to $2.6 \mathrm{l} / \mathrm{m}$ while the aneurysm enlarged, but factors involving myocardial contractility must also be considered as responsible for this. Surgery was not feasible since there was no precise information concerning 
TABLE 1

Ten cases of post-infarction cardiac aneurysm: clinical radiological, electrocardiographic and pathological features

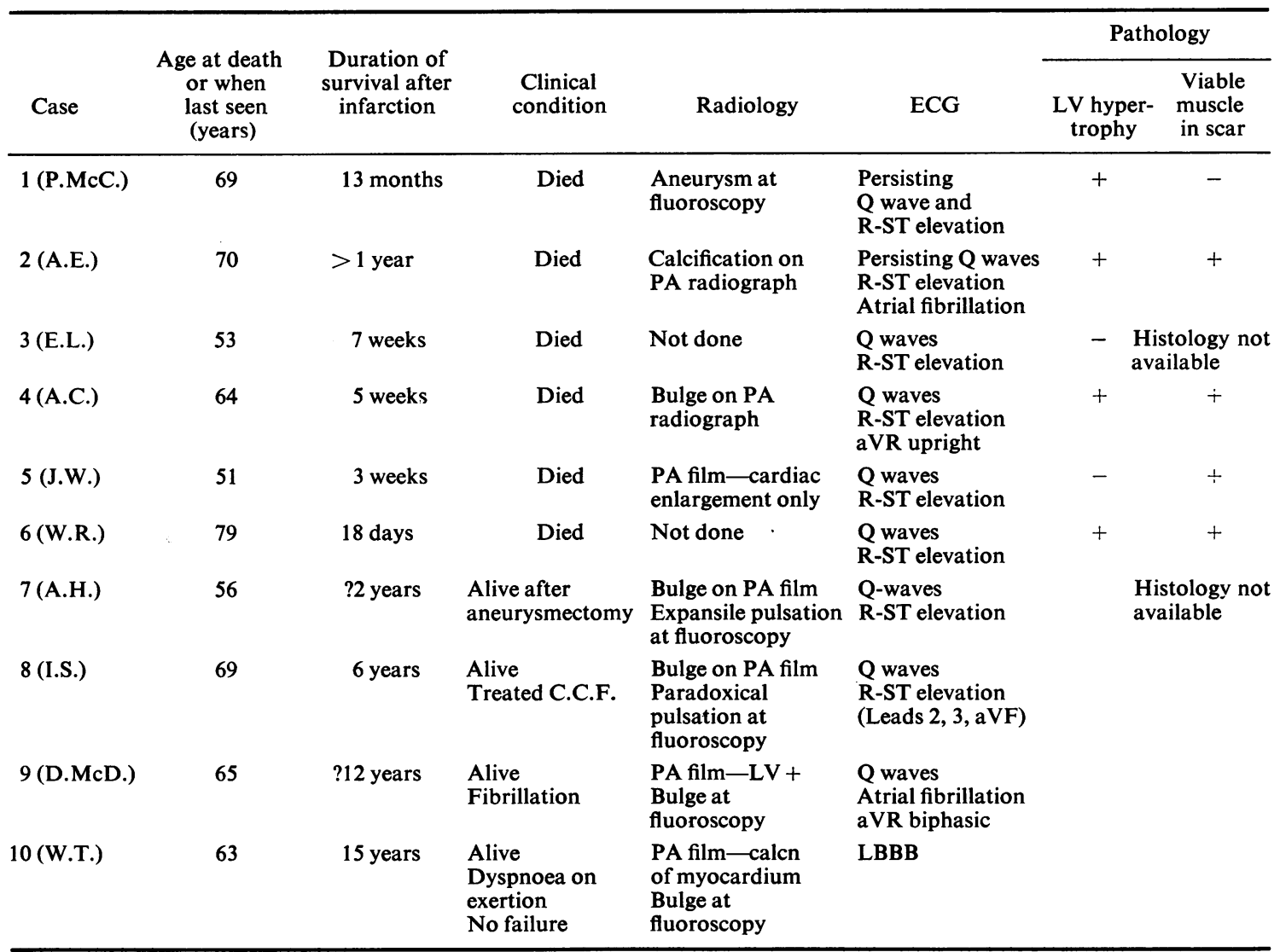

the extent of the recent infarction and whether suture would be possible after the aneurysm had been excised. The patient who was submitted for surgery has done reasonably well.

From a review of the literature and from our own observations we feel that the indications for surgery are as follows:

(1) Expansile cardiac aneurysm with persistent cardiac failure not responding to medical treatment.

(2) Repeated systemic emboli not controlled by anticoagulant treatment.

We would be reluctant to recommend operation on a heart in which there is fresh infarction before organization of the necrotic tissue has taken place. It would appear that at least 6 weeks and possibly 3 months would have to elapse before this has occurred (Mallory, White \& Salcedo-Salgar, 1939). Since organization takes place from the periphery of the aneurysm, surgery might be considered even in the early stages after the infarct, in cases with a poor immediate prognosis.

Although the physical findings associated with aneurysm are well known and have been fully described previously (Parkinson et al., 1938) the diagnosis is seldom made in life (Holmes \& MacFadyen, 1964). In this series of ten cases only one patient demonstrated clinical features which suggested a diagnosis of aneurysm. It was possible to make a diagnosis of cardiac aneurysm from the postero-anterior and lateral radiographs of six of the ten cases. In another case cardiac enlargement was noted radiologically and with the lack of sequential change on the ECG, cardiac aneurysm was suspected. We have found careful cardiac fluoroscopy using an image intensifier television system to be useful in detection of even small cardiac aneurysms (Groden \& James, 1968). Although recent reports have indicated the value of angio- 
graphy (Holmes \& MacFadyen, 1964 ; Björk, 1966 Steinberg, 1966; Gorlin et al., 1967), it was not necessary in any of the patients described here. In many of the reports in which angiography has been used the diagnosis was apparent from conventional radiological examination. If surgery were contemplated on the basis of the indications discussed above we would proceed to ventriculography and coronary arteriography would be carried out at the same time in order to assess the state of vascularity of the myocardium.

Persistent $Q$ waves and R-ST elevation more than 6 months after infarction are said to be highly suggestive of aneurysm formation (Rosenberg \& Messinger, 1949; Ford \& Levine, 1951 ; Moyer \& Hiller, 1951 ; Douglas et al., 1962). This phenomenon was present in all but one of the cases who had long-standing aneurysms. Sequential changes were noted to be absent in the electrocardiogram of those patients who died in the early stages after the infarction. The reason for persistent R-ST elevation is not clear but several hypotheses have been put forward. Ford \& Levine (1951) suggest either: (1) that there is a layer of ischaemic subendocardial muscle in these hearts and that an intraventricular ECG would display $\mathrm{R}$-ST elevation which is recorded on the anterior surface through the 'aneurysmal window', or (2) that R-ST elevation results from the pericarditis which commonly exists in these cases. Moyer \& Hiller (1951) suggest that hypertrophy of the surrounding muscle is responsible. Table 1 gives an indication of the frequency of these findings in our cases. An upright QRS in aVR in the presence of LV hypertrophy has also been reported to be suggestive of aneurysm (Goldberger \& Schwartz, 1948 ; Ford \& Levine, 1951). This was present in one of our patients (Case 4) and aVR was biphasic in another (Case 9).

\section{Acknowledgments}

We would like to express our gratitude to the Physicians of the Southern General Hospital for permission to report details of patients under their care, and to $\mathrm{Mr} \mathrm{T}$. Welsh for providing us with the operation notes on Case 7. We would also like to acknowledge the assistance and helpful advice of Dr Gavin Shaw in the preparation of the manuscript and of Dr A. Dick of the Department of Pathology.

\section{References}

Abrams, D.L., Edelist, A., Luria, M.H. \& Miller, A.J. (1963) Ventricular aneurysm; a re-appraisal based on a study of sixty-five consecutive autopsied cases. Circulation, 27, 164.

BJöRK, L. (1966) Roentgen diagnosis of left ventricular aneurysm. Amer. J. Roentgenol. 97, 338.

Douglas, A.M., Sferrazza, J. \& Marici, F. (1962) Natural history of aneurysm of ventricle. N.Y. St. J. Med. 62, 209.

Dubnow, M.H., Burchell, H.B. \& Titus, J.L. (1965) Post infarction ventricular aneurysm. Amer. Heart J. 70, 753.

FORD, R.V. \& LEVINE, H.D. (1951) The electrocardiographic clue to ventricular aneurysm. Ann. intern. Med. 34, 998.

Goldberger, E. \& Schwartz, S.P. (1948) Electrocardiographic patterns of ventricular aneurysm. Amer. J. Med. 4, 243.

Gorlin, R., Klein, M.D. \& Sullivan, J.M. (1967) A prospective correlative study of ventricular aneurysm. Mechanistic concept and clinical recognition. Amer. J. Med. 42, 512.

Groden, B.M., Allison, A. \& Shaw, G.B. (1967) The management of myocardial infarction. The effect of early mobilisation. Scot. med. J. 12, 435.

Groden, B.M. \& JAMES, W.B. (1967) Radiological abnormalities in patients who have survived a myocardial infarcrion. Possible relationship to aneurysm formation. Brit. Heart J. 30, 236.

Holmes, R.B. \& MacFadyen, L.R. (1964) Aneurysms of the heart. J. Can. Ass. Radiol. 15, 110.

HUNTER, J. (1757) An account of the dissection of morbid bodies. A manuscript copy in the library of the Royal College of Surgeons. No. 32, 30-32.

Kurtzman, R.S. \& LofSTrom, J.E. (1963) Detection and evaluation of myocardial infarction by image amplifica tion and cine fluorography. Radiology, 81, 57.

Mallory, G.K., White, P.D. \& Salcedo-Salgar, J. (1939) The speed of healing of myocardial infarction; a study of the pathologic anatomy in seventy-two cases. Amer. Heart J. 18, 647.

Master, A.M., Gubner, R., Dack, S. \& Yaffe, H.L. (1940) The diagnosis of coronary occlusion and myocardial infarction by fluoroscopic examination. Amer. Heart J. 20, 475.

Moyer, J.B. \& Hiller, G.I. (1951) Cardiac aneurysm. Clinical and electrocardiographic analysis. Amer. Heart $J$. 41, 340.

Parkinson, J., Bedford, D.E. \& Thomson, W.A.R. (1938) Cardiac aneurysm. Quart. J. Med. 7, 455.

Rosenberg, B. \& Messinger, W.J. (1949) The electrocardiogram in ventricular aneurysm. Amer. Heart J. 37, 267.

Schlichter, J., Hellerstein, H.K. \& Katz, L.N. (1954) Aneurysm of the heart. A correlative study of one hundred and two proved cases. Medicine (Baltimore), 33, 43.

Steinberg, I. (1966) Angiocardiographic findings in ventricular aneurysm due to arteriosclerotic myocardial infarction. Report of eleven cases. Amer. J. Roentgenol. 97, 321. 